\title{
ULF fluctuations of the geomagnetic field and ionospheric sounding measurements at low latitudes during the first CAWSES campaign
}

\author{
U. Villante ${ }^{1}$, M. Vellante ${ }^{1}$, P. Francia ${ }^{1}$, M. De Lauretis ${ }^{1}$, A. Meloni ${ }^{1}$, P. Palangio ${ }^{1}$, B. Zolesi ${ }^{1}$, M. Pezzopane ${ }^{1}$, \\ M. Förster ${ }^{2}$, T. L. Zhang ${ }^{3}$, W. Magnes $^{3}$, P. Nenovski ${ }^{4}$, I. Cholakov ${ }^{4}$, and V. Wesztergom ${ }^{5}$ \\ ${ }^{1}$ Consorzio Area di Ricerca in Astrogeofisica, L'Aquila, Italy \\ ${ }^{2}$ GeoForschungsZentrum, Potsdam, Germany \\ ${ }^{3}$ Space Research Institute, Austrian Academy of Sciences, Graz, Austria \\ ${ }^{4}$ Geophysical Institute, Bulgarian Academy of Science, Sofia, Bulgaria \\ ${ }^{5}$ Geodetic and Geophysical Research Institute of the Hungarian Academy of Science, Sopron, Hungary
}

Received: 17 August 2005 - Revised: 17 January 2006 - Accepted: 21 April 2006 - Published: 3 July 2006

Part of Special Issue "The 11th International Symposium on Equatorial Aeronomy (ISEA-11), Taipei, May 2005"

\begin{abstract}
We present an analysis of ULF geomagnetic field fluctuations at low latitudes during the first CAWSES campaign (29 March-3 April 2004). During the whole campaign, mainly in the prenoon sector, a moderate Pc3-4 pulsation activity is observed, clearly related to interplanetary upstream waves. On 3 April, in correspondence to the Earth's arrival of a coronal mass ejection, two SIs are observed whose waveforms are indicative of a contribution of the high-latitude ionospheric currents to the low-latitude ground field. During the following geomagnetic storm, low frequency (Pc5) waves are observed at discrete frequencies. Their correspondence with the same frequencies detected in the radial components of the interplanetary magnetic field and solar wind speed suggests that Alfvénic solar wind fluctuations may act as direct drivers of magnetospheric fluctuations. A cross-phase analysis, using different pairs of stations, is also presented for identifying field line resonant frequencies and monitoring changes in plasmaspheric mass density. Lastly, an analysis of ionospheric vertical soundings, measured at the Rome ionosonde station $\left(41.8^{\circ} \mathrm{N}, 12.5^{\circ} \mathrm{E}\right)$, and vertical TEC measurements deduced from GPS signals within an European network shows the relation between the ULF resonances in the inner magnetosphere and thermal plasma density variations during geomagnetically quiet conditions, in contrast to various storm phases at the end of the CAWSES campaign.
\end{abstract}

Keywords. Magnetospheric physics (Solar wind-magnetosphere interactions; MHD waves and instabilities) - Ionosphere (Ionosphere-magnetosphere interactions)

Correspondence to: U. Villante

(umberto.villante@aquila.infn.it)

\section{Introduction}

In the last several years, research activity has produced a significant improvement in the knowledge of the physical processes which are the foundation of the solar-terrestrial relationships and enable interdisciplinary progresses in understanding the Sun-Earth domain as a whole. One of the scopes of the first CAWSES Space Weather Campaign (29 March3 April 2004) consisted of a collaborative effort to combine measurements from satellite and ground-based magnetometer chains for a better definition of several aspects related to the ULF activity. ULF waves in the frequency range $\sim 1-$ $100 \mathrm{mHz}$ (or "magnetic pulsations", as they are usually referred to) represent an important aspect of the Sun-Earth relationships. Indeed, they play a significant role in the energy transfer from the solar wind (SW) to the magnetosphere and are an intrinsic signature of different processes taking place in the Earth's magnetosphere as, for instance, the large variety of waves typically observed during the development of geomagnetic storms and substorms (Posch et al., 2003; Olson, 1999). In addition, ULF waves recorded at a dense latitudinal array can also be used to monitor the magnetospheric plasma mass density (Menk et al., 1999).

We contributed to this international campaign by conducting an analysis of ULF measurements at several low-latitude stations. In particular, we focused our attention on the Pc3 wave activity $(22-100 \mathrm{mHz})$ in the whole period, and on the appearance of lower frequency modes at discrete frequencies in the Pc5 range $(1.6-6.6 \mathrm{mHz})$ during the geomagnetic storm which occurred on 3 April 2004. We also present the results of cross-phase analysis using different pairs of stations which allows one to identify the field line resonant

Published by Copernicus GmbH on behalf of the European Geosciences Union. 

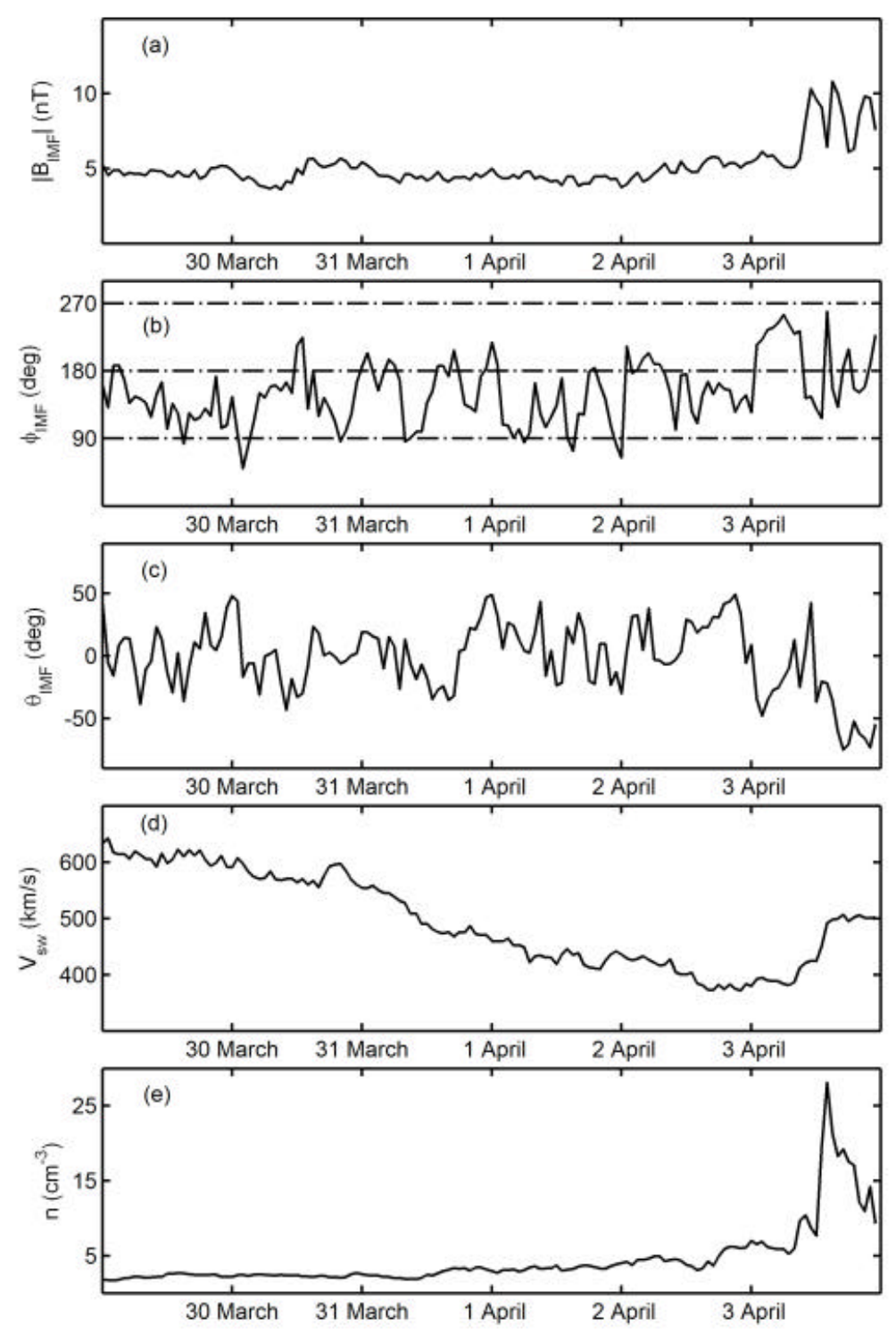

Fig. 1. Hourly averages of the interplanetary parameters as measured by ACE during 29 March-3 April 2004. Starting from the top: IMF strength, longitude (the angle between the IMF component in the ecliptic plane and the Sun-Earth direction) and latitude (the IMF inclination on the ecliptic plane), SW speed and number density.

frequencies and to infer the variations of the plasmaspheric mass density following the geomagnetic storm, an aspect which is very important in the space weather context. Ionospheric vertical soundings, as well as vertical TEC measurements are also analyzed and compared with plasmaspheric density estimates deduced from ULF wave resonances during the storm phases.

\section{Data and instrumentation}

The geomagnetic field measurements discussed in the present investigation come from SEGMA (South European GeoMagnetic Array; Vellante et al., 2002). SEGMA is a low-latitude meridional magnetometer array which consists of three stations in Italy and one in Hungary, latitudinally equispaced between $L=1.57-1.89$. Each station is equipped with high sensitivity $(\sim 10 \mathrm{pT})$ triaxial fluxgate magnetometers recording the northward $(H)$, eastward $(D)$, and vertically downward $(Z)$ components of the geomagnetic field variations. An automatic acquisition system collects the data at $1 \mathrm{~s}$, with timing provided via GPS. For this campaign we also had available 1-s fluxgate measurements made at Ottana (Sardinia, Italy) and 1-s search-coil measurements at Panagyurishte (Bulgaria). The coordinates of all the stations are given in Table 1. 
Table 1. Coordinates of the ULF magnetic stations.

\begin{tabular}{|c|c|c|c|c|c|c|}
\hline \multicolumn{2}{|l|}{ Station } & \multicolumn{2}{|c|}{ Geographic Coord. } & \multicolumn{2}{|c|}{ Corr. Geomag. Coord. } & \multirow{2}{*}{$\begin{array}{l}L \\
\mathrm{R}_{E}\end{array}$} \\
\hline Name & Code & Lat. $\left[{ }^{\circ} \mathrm{N}\right]$ & Lon. $\left[{ }^{\circ} \mathrm{E}\right]$ & Lat. $\left[{ }^{\circ} \mathrm{N}\right]$ & Lon. $\left[{ }^{\circ} \mathrm{E}\right]$ & \\
\hline Nagycenk & NCK & 47.63 & 16.72 & 42.76 & 91.41 & 1.89 \\
\hline Castello Tesino & CST & 46.05 & 11.65 & 40.82 & 86.64 & 1.78 \\
\hline Ranchio & $\mathrm{RNC}$ & 43.97 & 12.08 & 38.26 & 86.57 & 1.65 \\
\hline L'Aquila & AQU & 42.38 & 13.32 & 36.30 & 87.35 & 1.57 \\
\hline Panagyurishte & PAG & 42.51 & 24.18 & 36.98 & 97.21 & 1.59 \\
\hline Ottana & OTN & 40.26 & 8.97 & 33.40 & 83.17 & 1.46 \\
\hline
\end{tabular}

For a comparison with the interplanetary medium conditions we considered the SW and interplanetary magnetic field (IMF) parameters from the ACE spacecraft at the L1 libration point upstream of the Earth.

Fifteen-minute ionospheric measurements are routinely carried out at the ionospheric station of Rome $(41.8 \mathrm{~N}$, $12.5 \mathrm{E})$. The ionograms, visible at the site http://dps-roma. ingv.it/, are recorded by a Digital Portable Sounder (DPS) (Reinisch, 1996) and automatically scaled by the ARTIST system (Reinisch and Huang, 1983). For our purposes the automatically scaled values of $f o \mathrm{~F} 2$ (the critical frequency of the F2 layer) from 31 March to 5 April 2004 were validated using the Interpre software (Pezzopane, 2004).

We also used vertical Total Electron Content (TEC) measurements over Northern Italy as deduced from recordings of GPS signals, using receiving stations of the International GPS Service (IGS) all over Europe. They are compiled as regional maps of the European sector within the bounds from $20^{\circ} \mathrm{W}$ to $40^{\circ} \mathrm{E}$ geographic longitude and $35^{\circ}-70^{\circ} \mathrm{N}$ latitude (see http://www.kn.nz.dlr.de/tec_mon). We used TEC maps with a 30-min time resolution. They combine measurements from about 70-110 independent GPS data links for the construction of each TEC pattern in combination with a suitable background model (Jakowski, 1996).

\section{The temporal pattern of Pc3 wave activity}

In general, at middle and low latitudes, most aspects of the ground Pc3 manifestations are interpreted in terms of penetration of upstream waves, generated by ions reflected off the bow shock along the IMF lines, and related field line resonance (FLR) phenomena (Yumoto, 1986). An important argument in favor of the upstream wave source is the generally observed linear relation between the frequency of ground pulsations and the IMF strength, i.e. $f[\mathrm{mHz}] \sim 6 \cdot B_{I M F}[\mathrm{nT}]$ (Troitskaya and Bolshakova, 1988). In addition, the IMF orientation also plays a significant role in that ground pulsations occur more frequently when the cone angle (the angle $\theta_{X B}$ between the IMF and the Sun-Earth line) is small, suggesting a direct transmission of waves from the subsolar bow shock (Russell et al., 1983).

The interplanetary medium conditions during the campaign are shown in Fig. 1. As can be seen, from 29 March to 2 April, the IMF strength is $\sim 5 \mathrm{nT}$, its direction fluctuates both in longitude and in latitude, the SW speed monotonically decreases from $\sim 600 \mathrm{~km} / \mathrm{s}$ to values smaller than $400 \mathrm{~km} / \mathrm{s}$ and the number density is lower than $5 \mathrm{~cm}^{-3}$. On 3 April at 08:55 UT, ACE observed the arrival of a coronal mass ejection (CME).

Figure 2 illustrates the time behaviour of the ULF wave activity during the whole CAWSES campaign at NCK (MLT $\sim \mathrm{UT}+1: 40$ ); a similar behaviour also is observed at the other stations of the array. We show here the $D$ component, which is less affected, with respect to the $H$ component, by local FLR. As typical at these latitudes, Pc3 wave activity is observed in the form of distinct wave packets; the dominant frequency is $\sim 30 \mathrm{mHz}$ which, according to the above-mentioned empirical relation, closely corresponds to the expected upstream wave frequency for an IMF magnitude of $\sim 5 \mathrm{nT}$. At the top of each spectrum, we show the hourly average of the cone angle with red (blue) lines, indicating favourable (unfavourable) conditions for upstream wave transmission in the magnetosphere in correspondence to $\theta_{X B}$ values lower (higher) than $50^{\circ}$ (Greenstadt and $\mathrm{Ol}-$ son, 1979). As can be seen, distinct amplitude enhancements mostly occur in the morning sector and are often associated with small cone angles, while in the afternoon sector the wave activity is negligible, independent on $\theta_{X B}$.

This kind of morning/afternoon asymmetry was suggested by Greenstadt (1973) to be caused by the average spiral orientation of the IMF lines which would create the quasiparallel shock region (where upstream waves are generated), preferentially in the morning side. However, Takahashi et al. (1981) found, at geosyncronous orbit, a higher occurrence of Pc3 pulsations in the morning, independent of the IMF orientation.

In our case, a clear example of strong morning/afternoon asymmetry in the Pc3 wave amplitude which is not explained by the Greenstadt (1973) argument, is observed on 31 March. On this day, during the morning 

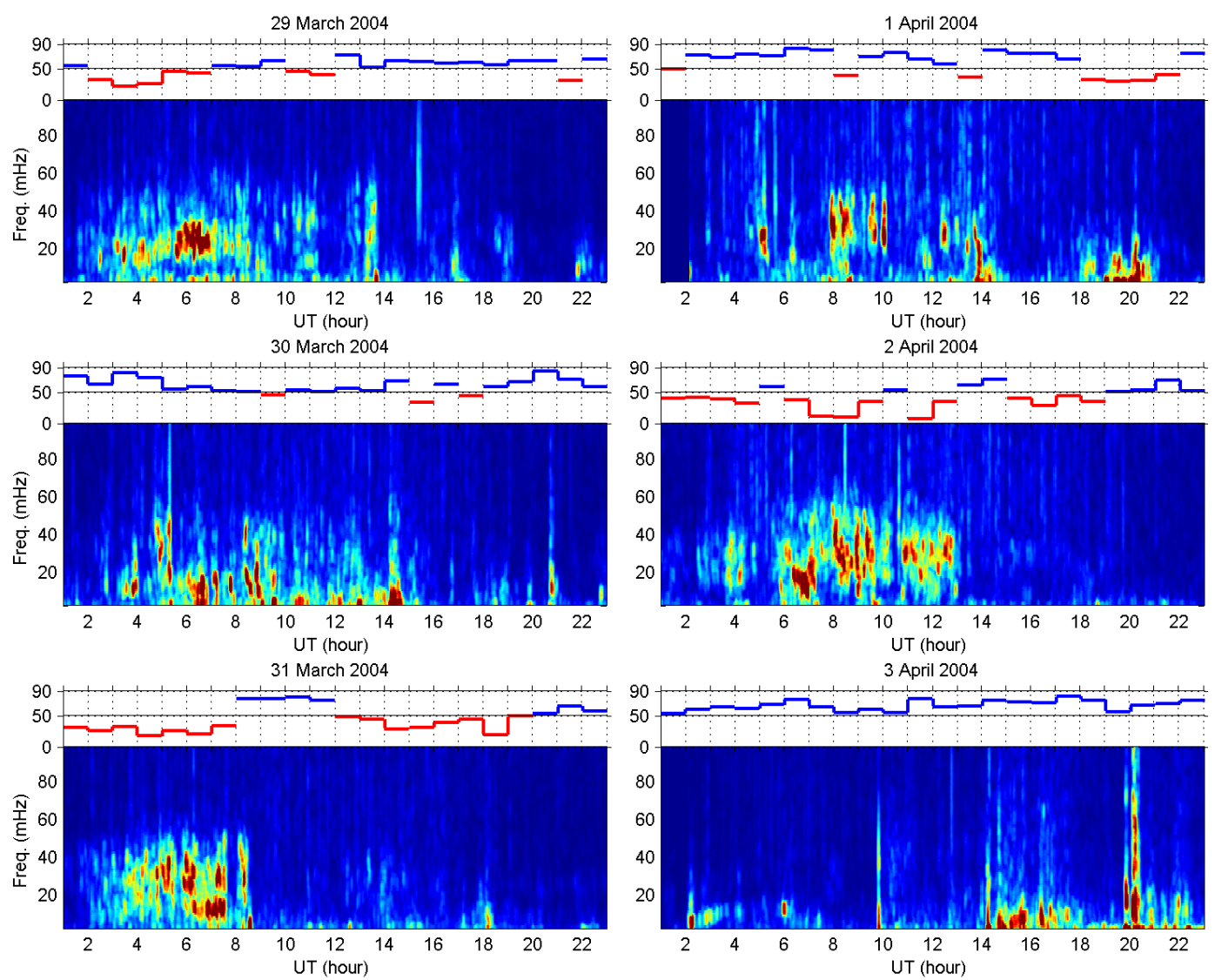

Fig. 2. Dynamic amplitude spectra of the $D$-comp. at NCK. Data have been time differenced before spectral processing to better visualize Pc3 $(20 \mathrm{mHz}-100 \mathrm{mHz})$ wave activity. The amplitude scale is different for each day. Hourly values of the cone angle (taking into account the propagation delay from ACE spacecraft to the magnetopause) are shown at the top of each spectrum. Favourable (unfavourable) conditions for upstream wave transmission in the magnetosphere are evidenced by the different colour: red (blue) for $\theta_{X B}$ lower (higher) than $50^{\circ}$.

(04:00-07:00 UT) and afternoon (14:00-18:00 UT) hours, there is similar favourable $\theta_{X B}$ (Fig. 2), and the IMF longitude $\left(\phi \sim 180^{\circ}\right.$, Fig. 1) should not provide a morning or an afternoon preference. This indicates that some other mechanism has to be considered for the preferential morning occurrence of $\mathrm{Pc} 3$ pulsations.

\section{Arrival at Earth of the 3 April CME}

On 3 April a CME arrived at $~ 08: 55$ UT at the ACE position (Fig. 3). As can be seen, the IMF strength changes from $\sim 5$ to $\sim 8 \mathrm{nT}$, the $B_{x}$ and $B_{y}$ components become highly variable, $B_{z}$ increases to large positive values $(\sim 12 \mathrm{nT})$ until $\sim 10: 48$ UT, then decreases, becoming negative at $\sim 11: 10$ UT. After the IMF southward turning, ground observations show the development of a moderate geomagnetic storm. The SW pressure shows two sharp, positive variations at $\sim 08: 58$ UT and $\sim 13: 12$ UT (downward arrows) which find clear correspondence in two SIs observed on the $H$ component of the geomagnetic field at SEGMA stations at 09:47 UT and 14:10 UT (upward arrows). The time delay between the SW pressure variation and the SI occurrence is $\sim 51$ and $\sim 58$ min, respectively. While for the second SI the observed time delay can be considered consistent with a radial propagation of the SW structure ( $\sim 50 \mathrm{~min}$ to the subsolar bow shock, plus the propagation time through the magnetosheath and the magnetosphere), for the first SI the time delay is lower than the estimated one $(\sim 56 \mathrm{~min}$ to the subsolar bow shock) suggesting a SW discontinuity inclined at a large angle $\left(\sim 60-65^{\circ}\right)$ with respect to the radial direction (Villante et al., 2004).

As shown in the bottom left panel, the first SI (a similar behaviour, although less explicit, is also identified for the second SI, bottom right panel) is characterized by a complex behaviour of the $H$ component, with two successive pulses of opposite sign (negative/positive) preceding a further increase, and then a longer term decrease to a new steady state. Such complex behaviour confirms (Villante et al., 2005a) that at $L \sim 1.6-1.9$ the SI signal cannot be interpreted in terms of the magnetopause current alone (DL field): if this would be the case, indeed, the experimental measurements should only 


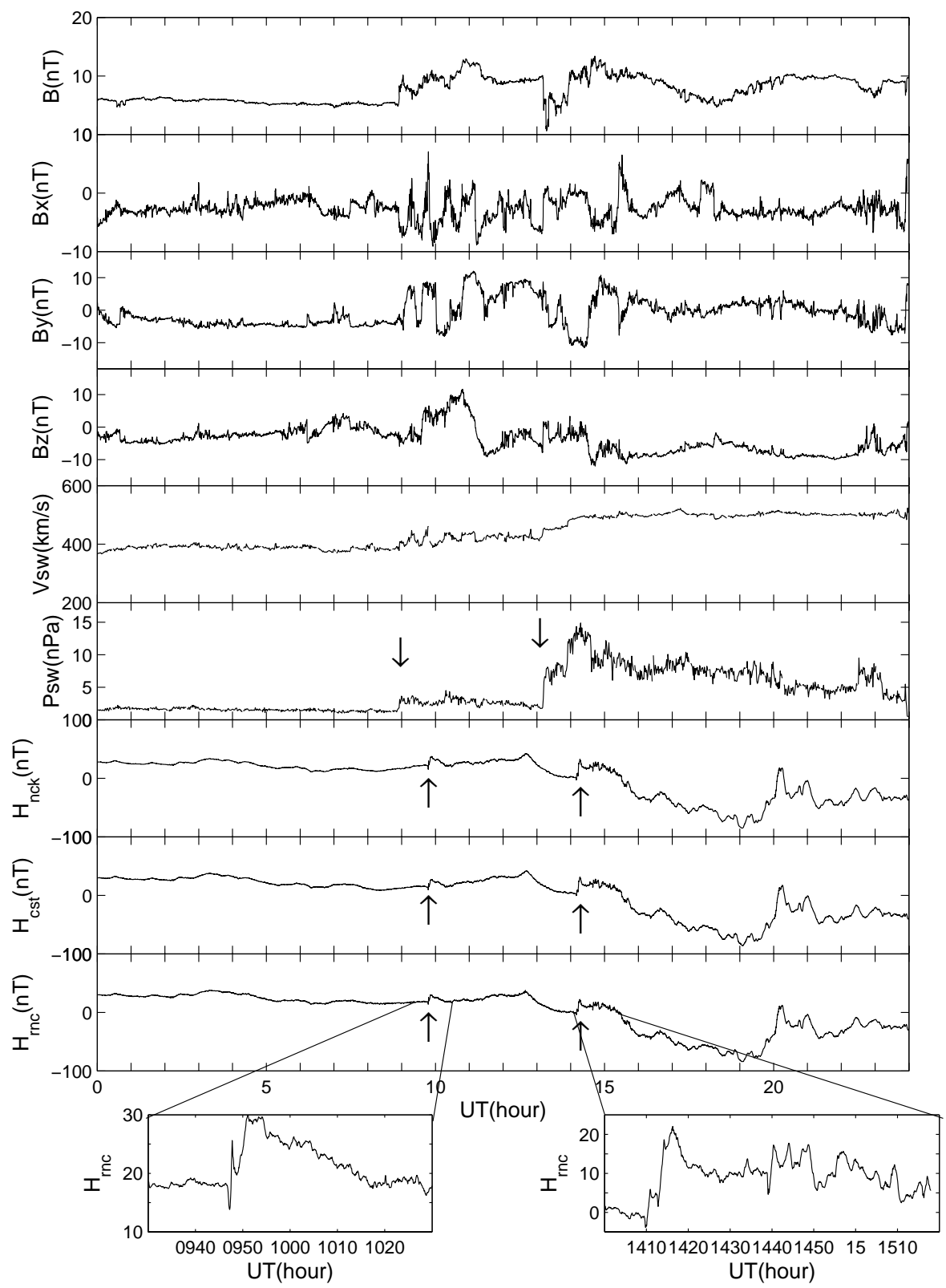

Fig. 3. ACE measurements and ground observations on 3 April 2004. From top to bottom are shown the IMF strength and its components in GSE coordinates, the SW speed and dynamic pressure, the $H$ component at the SEGMA stations NCK, CST and RNC (data are not available at AQU during this day). Details of the two SIs observed at RNC are shown in the two bottom panels.

reveal a simple positive variation, with amplitude decreasing with increasing latitude. Complex waveforms of the $H$ signal are commonly observed at auroral latitudes, where in the morning a positive pulse typically precedes and a negative pulse follows, and the sense of the pulses is reversed in the afternoon. According to model predictions (for example, Araki, 1994), similar structures are interpreted in terms of additional fields (globally identified as DP field) produced by high-latitude ionospheric currents; briefly, in this scheme, the magnetospheric electric fields, due to the compressional wave front, are transmitted to the polar ionosphere through field-aligned currents which drive twin, time-dependent vortex currents in the morning and afternoon sector, respectively. On the other hand, in agreement with the present results, the low-latitude extension of the DP fields has been reported in previous investigations (Kikuchi and Araki, 1985; Tsunomura, 1998; Villante et al., 2005a): in the present case, the occurrence of the initial negative pulse might lead to speculate, for the period of interest, a latitudinal and MLT extension of the afternoon vortex larger than the morning 


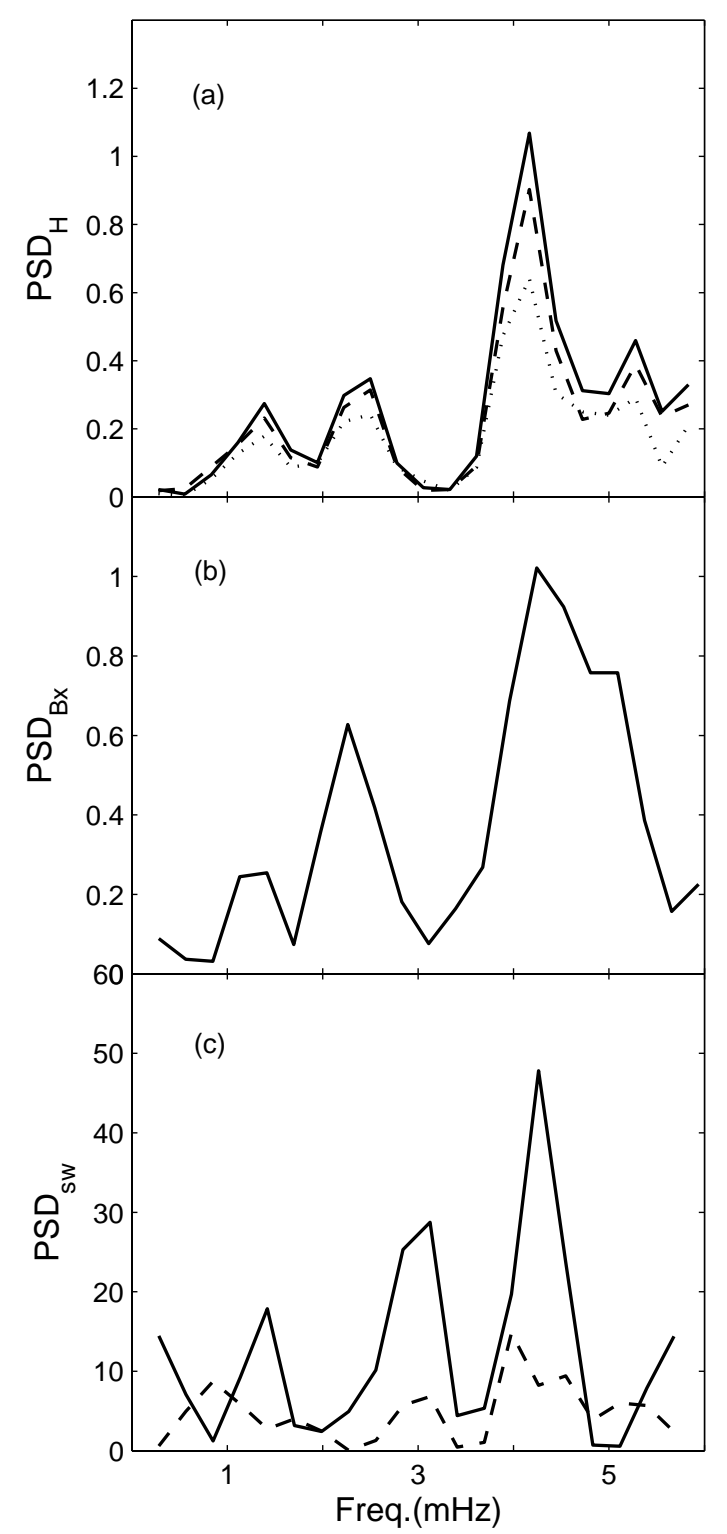

Fig. 4. (a) Power spectral density of the H component at NCK (solid line), CST (dashed line) and RNC (dotted line) in the time interval 14:18-15:18 UT on 3 April 2004; (b) power spectral density of the IMF $\mathrm{B}_{x}$ component time shifted by $-1 \mathrm{~h}$; (c) power spectral density of the SW speed (solid line) and density (dashed line) time shifted by $-1 \mathrm{~h}$.

one, a situation predicted by Araki (1994) as a consequence of the different morning and afternoon conductivity. As to the amplitude of the geomagnetic response, the comparison of different stations suggests a steady-state response $\Delta H$ (as evaluated $5 \mathrm{~min}$ after the peak response) decreasing with decreasing latitude as $\sim 1 \mathrm{nT} /{ }^{\circ}$ : as previously underlined, this behaviour is odd with respect to predictions for the DL field alone and also confirms a significant contribution of the DP field on the longer term variation (Villante and Di Giuseppe, 2004; Villante et al., 2005a).

\section{Low frequency magnetospheric modes during the storm}

As shown in Fig. 3 (see also the bottom right panel), at SEGMA stations the $H$ component exhibits evidence for a long period of irregular wave activity following the second SI. This aspect is confirmed by a spectral analysis conducted over consecutive, overlapping, 1-h intervals for the entire day, which reveals significant spectral enhancements, in particular, between 14:00-16:00 UT; in this analysis we used Welch's periodogram method, and the geomagnetic data were differenced in order to eliminate the lowest frequency variations, so that spectral features could be more clearly identified in the frequency range of interest. Figure 4a shows, in particular, a comparison of the power spectra at NCK, CST and RNC for the time interval 14:18-15:18 UT in which spectral features more explicitly emerge; as can be seen, spectral peaks clearly appear at the same discrete frequencies, namely $\sim 1.4,2.2-2.5$, and $4.2 \mathrm{mHz}$; in addition, their amplitude increases with latitude, as expected for compressional modes driven by an external source.

The observed peak frequencies roughly correspond to the "selected" frequencies of Pc5 pulsations, which have been currently interpreted in terms of magnetospheric cavity/waveguide modes. Indeed, when excited by impulsive variations of the SW pressure, the magnetosphere can behave as a cavity, oscillating at its own eigenfrequencies which depend on its dimensions and physical characteristics (Radoski, 1974; Kivelson and Southwood, 1985; 1986). This model has been extended by Samson et al. (1992) and Walker et al. (1992), who considered the magnetosphere as an openended waveguide in which compressional modes driven by the SW propagate antisunward. Several investigations at auroral latitudes reported evidence for long period waves at "selected" frequencies of $\sim 1.3,1.9,2.6,3.4$, and $4.2 \mathrm{mHz}$, which were interpreted in terms of local FLRs excited by the compressional cavity modes (Samson et al., 1991; Ziesolleck and McDiarmid, 1995; Mathie et al., 1999). Evidence for similar signals was also reported at low-latitudes (Ziesolleck and Chaumalaun, 1993; Francia and Villante, 1997; Villante et al., 2001). More particularly, studies of individual events showed that oscillations at "selected" frequencies were often associated with the arrival of CMEs and extended to a major portion of the Earth's magnetosphere (Shimazu et al., 1995; Villante et al., 1998; Lepidi et al., 1999). In this framework, the present discrete frequency fluctuations might be considered as the low-latitude signatures of cavity/waveguide modes driven by the impact of the SW pulse on the magnetopause.

However, more recently, several cases have been presented in which fluctuations in the SW density and in the magnetospheric field were highly correlated and often matched some of the "selected" frequencies, suggesting that these fluctuations might be an inherent property of the SW (Kepko et al., 2002; Kepko and Spence, 2003). In particular, Kepko and 
April 3, 2004
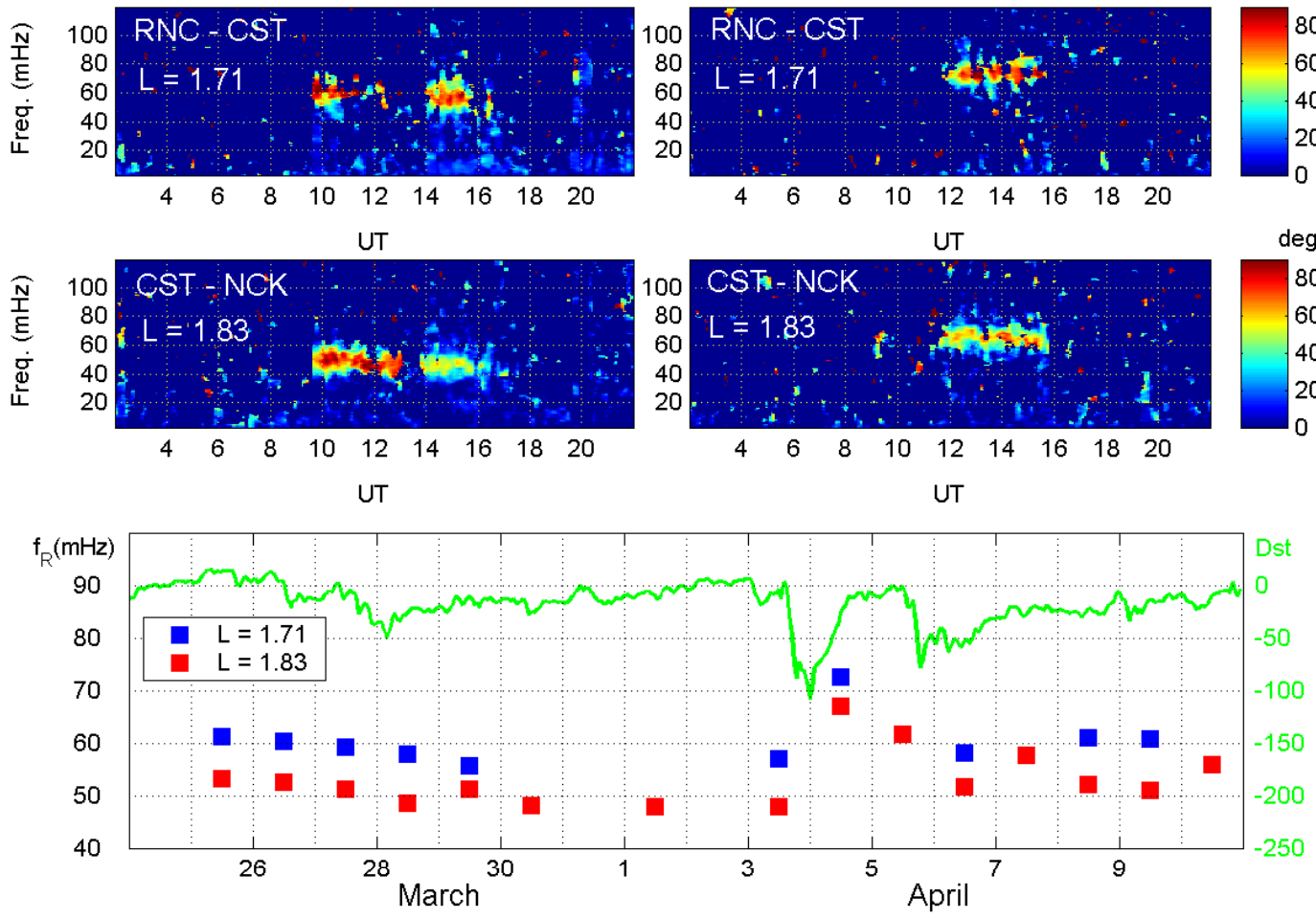

Fig. 5. Top: Dynamic cross-phase spectra of the $H$ component for two station pairs of the SEGMA array. Bottom: $D$ st index (green line) and daily averages (over the daytime interval 09:00-16:00 LT) of the resonant frequency at $L=1.83$ (red squares) and 1.71 (blue squares).

Spence (2003) speculated the possibility that solar oscillations might be the ultimate source for the periodicities observed in the SW and magnetosphere. Their analysis, however, did not include ground observations. On the other hand, a clear correlation between the variations of the $H$ component and the variations of the SW dynamical pressure on time scales of few minutes was found in a case study by Francia et al. (1999). This aspect has been corroborated recently by Villante et al. (2005b), who presented a joint analysis of SW, magnetospheric and ground observations, and showed that remarkable ground events at "selected" frequencies found a clear correspondence in the magnetospheric field at geostationary orbit, as well as in the SW density (and dynamical pressure). In addition, Kessel et al. (2004) found ULF fluctuations in the Pc5 range in high speed streams, compressional in the leading edge and Alfvènic in the central region. In general, both the compressional and transverse power correlated well with the Pc5 power of the $H$ component, as measured at KIL $\left(66^{\circ} \mathrm{N}, \mathrm{CGM}\right)$ over a 5 -month period of high speed SW streams. However, the correspondence between individual spectral features was poor, and SW and ground frequencies were not the same, though they generally were within the same range $(1-4 \mathrm{mHz})$, occasionally coincident with the cavity mode frequencies.
In order to investigate these aspects we also analyzed the IMF and SW data in the corresponding time-shifted interval 13:14-14:13 UT. As shown in Fig. 4b, the power spectra of the IMF radial component $B_{x}$ reveals the same power peaks of the $H$ component (at $\sim 1.4,2.2$ and $4.2 \mathrm{mHz}$ ), while no correspondence is observed for $B, B_{y}$ and $B_{z}$ (not shown). Meanwhile, the SW speed fluctuations (radial component, $V_{x}$ ) are also characterized by power peaks at $\sim 1.4$ and $\sim 4.2 \mathrm{mHz}$ (Fig. 4c, solid line) while a third peak occurs around $\sim 3 \mathrm{mHz}$. Conversely, minor peaks at different frequencies (at $\sim 0.8,1.7,3$ and $4 \mathrm{mHz}$ ) appear in the power spectrum of the SW density (Fig. 4c, dashed line). In addition, it is interesting to note that in the time interval 13:35-13:46 UT, in which the SW fluctuations at the dominant frequency $(\sim 4.2 \mathrm{mHz})$ more clearly appear, $B_{x}$ and $V_{x}$ were highly correlated $(\rho=0.92)$, and, correspondingly, the ratio between the IMF strength variance and total variance of the field components was $\sim 0.03$; all these aspects might be considered indicative of the Alfvènic character of the observed fluctuations. These fluctuations found a clear correspondence in the time-shifted interval of the $H$ component. 
Table 2. Resonant frequencies and corresponding equatorial densities.

\begin{tabular}{llllll}
\hline $\mathrm{L}$ & $\mathrm{f}_{R}(3$ April $)$ & $\mathrm{f}_{R}(4$ April $)$ & $\rho_{1}=\rho_{o}(3$ April $)$ & $\rho_{2}=\rho_{o}(4$ April $)$ & $\rho_{1} / \rho_{2}$ \\
\hline 1.71 & $57 \mathrm{mHz}$ & $73 \mathrm{mHz}$ & $7800 \mathrm{amu} / \mathrm{cc}$ & $4800 \mathrm{amu} / \mathrm{cc}$ & 1.6 \\
1.83 & $48 \mathrm{mHz}$ & $67 \mathrm{mHz}$ & $5900 \mathrm{amu} / \mathrm{cc}$ & $3000 \mathrm{amu} / \mathrm{cc}$ & 2.0 \\
\hline
\end{tabular}
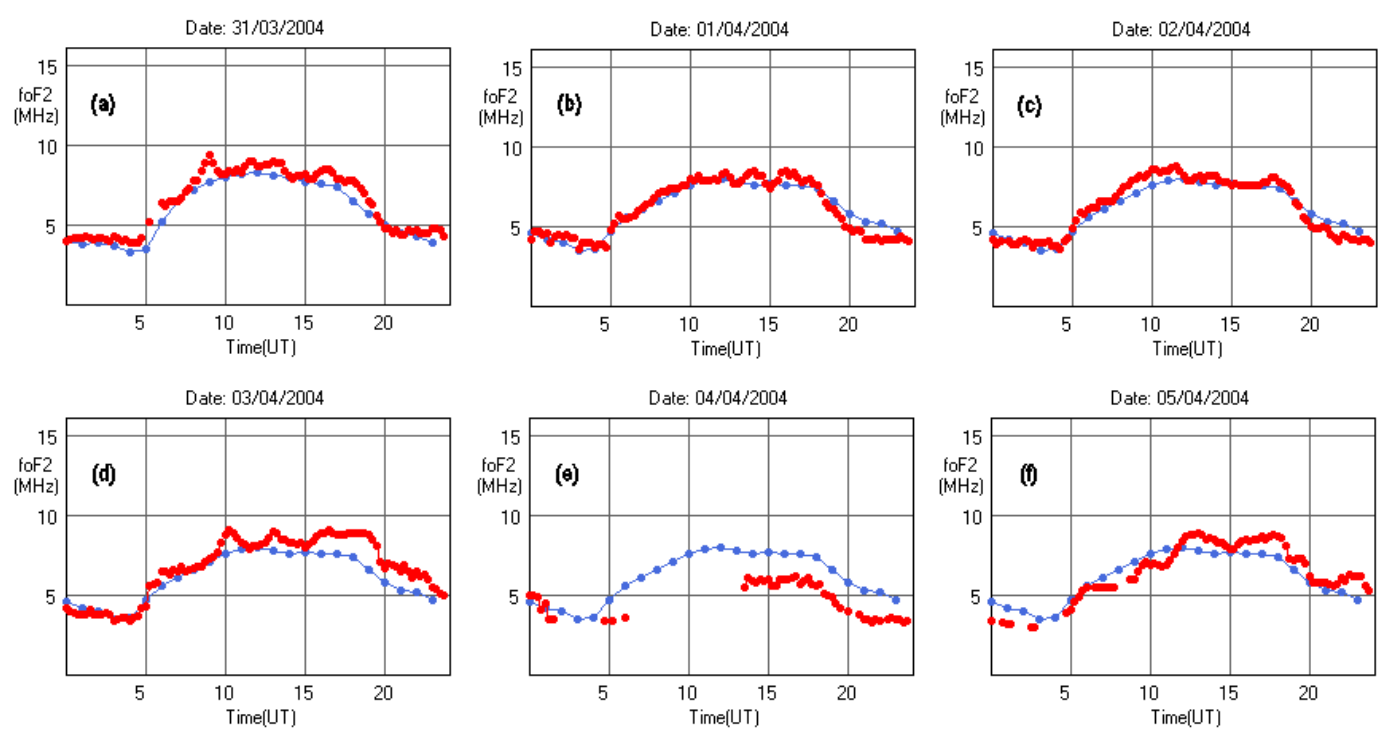

Fig. 6. Validated $f o \mathrm{~F} 2$ values (in red), as obtained by the ionograms recorded in Rome from 31 March to 5 April 2004, compared to the corresponding foF2 hourly median values (in blue) predicted by SIRM model and here assumed as quiet-day values.

\section{Remote sensing of the plasma mass density by geo- magnetic field line resonances}

In the last recent years there has been increasing use of ground-based ULF magnetic measurements to remote sense the plasma mass density in the magnetosphere (Menk et al., 1999; Chi et al., 2000; Clilverd et al., 2003; Berube et al., 2005). This method consists of determining the frequency of the eigen-oscillations of a given geomagnetic field line (usually the field line midway between two latitudinally separated recording stations). From the measurement of the field line resonance frequency $f_{R}$, an estimate of the plasma mass density (usually at the equatorial point of the given field line) can be inferred. The spatial configuration of the SEGMA array (four stations latitudinally equispaced with an interstation separation of $\sim 2^{\circ}$ ) is particularly suitable for accurate $f_{R}$ determinations. It allows a monitoring of the mass density in the inner plasmasphere, where in-situ spacecraft measurements are sporadic. We found it useful then to perform such a study which may provide additional important information in the framework of this multi-instrument coordinated campaign.

The $f_{R}$ estimates have been determined using the crossphase technique (Waters et al., 1991). This technique iden- tifies $f_{R}$ by the peak in the phase difference of the $H$ component between two stations with small latitudinal separation. Figure 5 (top) shows the phase-difference spectrograms for 3 April and 4 April, as obtained from the station pairs RNC-CST $(L=1.71)$ and CST-NCK $(L=1.83)$. Clear resonant signatures are visible in the form of bright traces for a few daytime hours on both days. A slight decrease of $f_{R}$ can be noted at both station pairs after $\sim 14: 00$ UT of 3 April, i.e. at the beginning of the main phase of the geomagnetic storm. More precisely, at both latitudes the $f_{R}$ value in the time interval 14:00-16:00 UT is $\sim 10 \%$ lower with respect to the value in the interval 09:45-11:00 UT. A more significant variation is observed when comparing the $f_{R}$ values of 4 April, i.e. during the recovery phase of the geomagnetic storm, with respect to the pre-storm values of 3 April. The bottom panel of Fig. 5 shows the temporal behaviour of the daily average of $f_{R}$ (over the daytime hours 09:00-16:00 LT) at $L=1.71$ and $L=1.83$, together with the Dst index (green line) for an extended interval, including the present campaign. As can be seen on 4 April, at both latitudes, $f_{R}$ is significantly higher with respect to normal conditions. The recovery to the pre-storm values occurs on 6 April (i.e. three days after the SSC). 


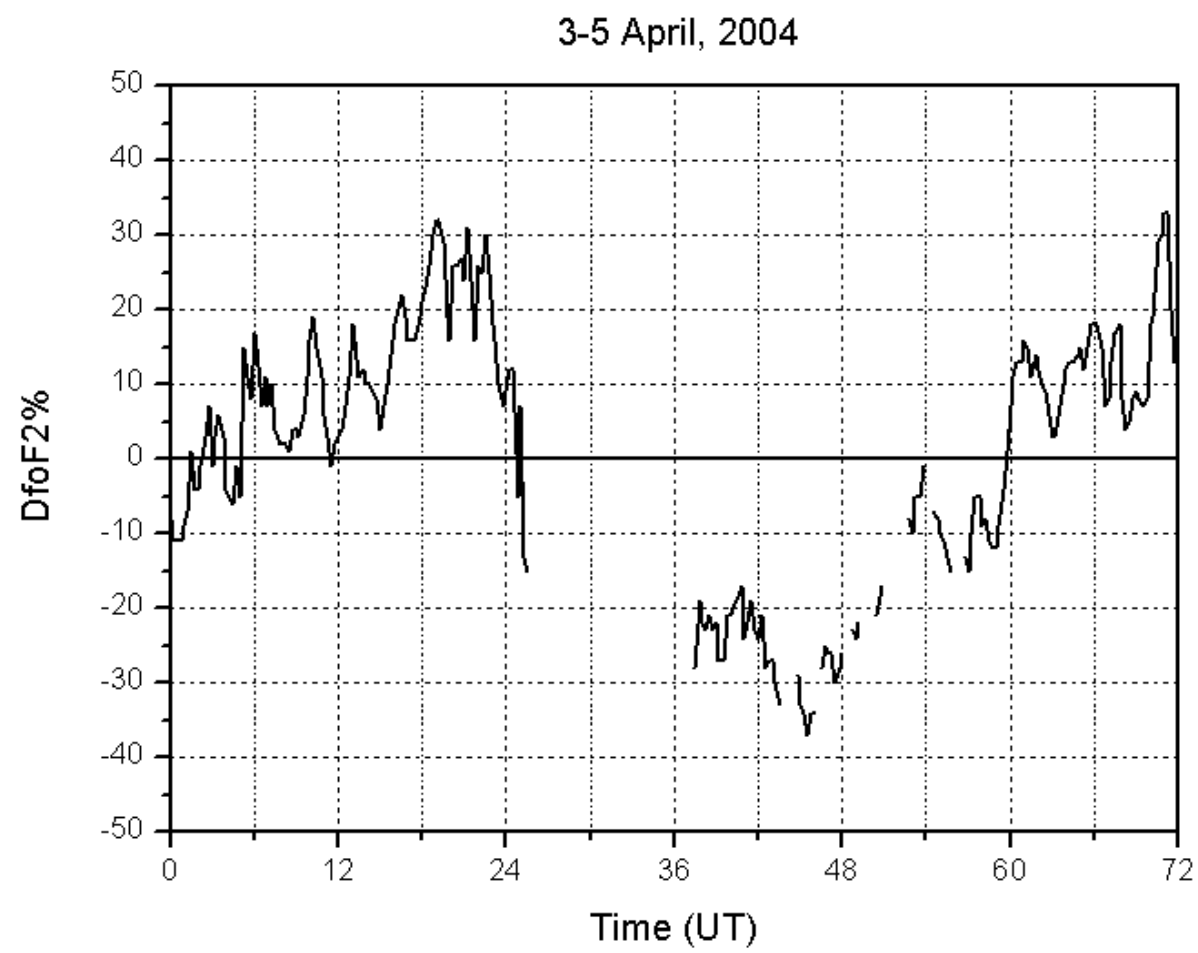

Fig. 7. Relative deviations, $\mathrm{D} f o \mathrm{~F} 2 \%$, of $f o \mathrm{~F} 2$ from the corresponding monthly median value during 3-5 April 2004.

Equatorial plasmaspheric mass densities $\left(\rho_{o}\right)$ given in Table 2 have been inferred from $f_{R}$, assuming, as is usually done, a radial power law dependence of the density along the dipole field line $\left(\rho \propto r^{-m}\right.$; Schulz, 1996). We have chosen $m=5$, which is a value higher than the values (3-4) typically used at higher latitudes (Menk et al., 1999; Chi et al., 2000). This choice was done in order to take into account that at our latitudes a significant fraction of the field line is characterized by a very steep density variation (Sutcliffe et al., 1987). In any case, the density ratio (last column in Table 2) is independent of the particular $\mathrm{m}$ value chosen; indeed, it can be derived from the simple relation $\rho_{o} \propto\left(f_{R}\right)^{-2}$ with the only assumption that the functional form of the field-aligned density distribution in the two cases is the same (Orr and Matthew, 1971). The results indicate a significant plasmaspheric depletion (by a factor of 1.6-2) on the day following the SSC. A similar effect (i.e. a depletion at an unexpected low $L$-shell) was previously found with the same ULF technique at $L=2$ by $\mathrm{Chi}$ et al. (2000) for the geomagnetic storm of 25 September 1998. For both storms the depletion (by a factor of 3 for the 25 September 1998 storm) is observed during the recovery phase with a prolonged phase of northward IMF. Similar density depressions (by a factor 23) have also been observed inside the plasmasphere during geomagnetic storms from whistler observations (Carpenter and Park, 1973) and from the Radio Beacon Experiment of the ATS-6 satellite (Degenhardt et al., 1977). A comparison between the present ULF wave observations and the corre- sponding ionospheric observations during the present geomagnetic storm is presented in the next section.

\section{Ionospheric sounding measurements}

To visualize the behavior of the ionosphere during the present campaign, in Fig. 6 the observed 15-min foF 2 values at the Rome station are drawn in comparison with the longterm prediction of the hourly median values, calculated using the Simplified Ionospheric Regional Model (SIRM; Zolesi et al., 1996), here assumed as quiet-day values. Pre-storm conditions are illustrated in Figs. 6a, b, and c. Figure $6 d$ shows how the geomagnetic storm onset (Fig. 3) is followed by a weak, positive ionospheric storm in the afternoon hours of 3 April 2004. Then, through the whole 4 April (Fig. 6e), it follows a phase in which foF 2 is depressed below its median value (a so-called "negative storm"). These variations of $f_{o} \mathrm{~F} 2$ (also called the "decrease type") usually accompany geomagnetic disturbances at higher middle-latitudes (Matsushita, 1959). The ionospheric disturbance magnitude is shown in Fig. 7 in terms of the relative deviation ( $\mathrm{D} f o \mathrm{~F} 2 \%$ ) of $f_{o} \mathrm{~F} 2$ from its quiet-day value. These values are very similar to those caused by neutral composition changes at middle latitudes (Buonsanto, 1999). Hence, it is possible to attribute the negative phase effects in Fig. 6e to the composition changes of the neutral atmosphere, specifically in the atomic/molecular ratio that alter the balance of the 

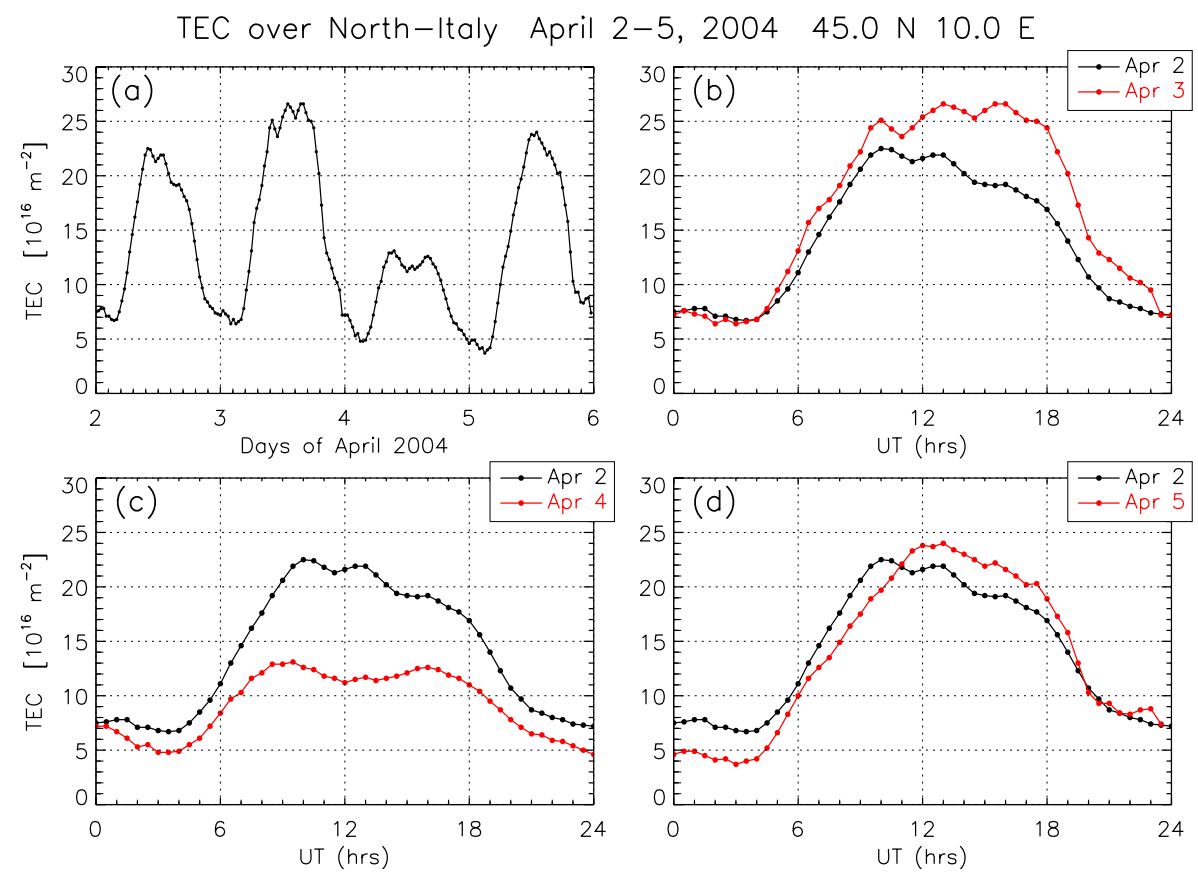

Fig. 8. (a) Vertical TEC measurements deduced from GPS signals using an European network of IGS stations for the time interval 25 April 2004 above Northern Italy at geographic coordinates of $45^{\circ} \mathrm{N}$ and $10^{\circ} \mathrm{E}$. In the other panels, the diurnal TEC variation of the geomagnetically quiet day 2 April 2004, is compared with different disturbance phases during the three subsequent days. This comparison shows a positive storm on 3 April, followed by a negative storm phase during about one and a half days on 4-5 April, after which a smaller, positive disturbance re-establishes at about 11:00 UT on 5 April.

production and loss processes of the ionised plasma (Rishbeth, 1998).

However, we need to take into account that other processes, in particular dynamic processes, such as electric field drifts and thermospheric neutral winds, contribute to the complexity of ionospheric storms (Prölss, 1995). Note also the missing data in Figs. 6e and 7 between 06:00 UT and 13:00 UT on 4 April, due to an absorption phenomenon that is typical for such a disturbed condition, because of D-layer ionization by precipitating charged particles (mainly highenergy electrons).

Dynamic processes dominate the thermal plasma behaviour at F2-layer heights and above, i.e. in the upper ionosphere and plasmasphere. They are also essential for the plasma exchange fluxes between the ionosphere and plasmasphere and for the temporary storage of plasma within co-rotating plasmaspheric flux tubes (Förster and Jakowski, 2000), whose filling status has been shown by the phasedifference measurements of resonant ULF waves in Sect. 6 (Fig. 5). Topside ionospheric and plasmaspheric measurements such as remote sensing techniques like radio occultation measurements, using low-Earth orbiting satellites (Jakowski et al., 2002; Heise et al., 2002) or TEC measurements between the satellites of the Global Positioning System (GPS) and ground-based receiving stations, can provide insight into these dynamic processes.

We therefore show in Fig. 8a the temporal variation of the vertical TEC (see Sect. 2) over Northern Italy at geographic coordinates of $45^{\circ} \mathrm{N}$ and $10^{\circ} \mathrm{E}$ for the time interval 2-5 April 2004. TEC reflects as an integral parameter both the ionospheric density variation, such as the F2-layer frequency maximum shown in Figs. 6 and 7, as well as the upper ionosphere and plasmaspheric density variations, to a varying extent.

In Figs. 8b, c, d we also compare the diurnal TEC variation of the geomagnetically quiet day 2 April 2004, with the disturbance conditions during the three subsequent days. The storm initiates with a prominent plasma density increase, the positive storm phase, just after the occurrence of the first SSC at 09:47 UT; then it reinforces drastically following the second SSC at 14:10 UT. The TEC increase gains more than $30 \%$ and persists until the early morning hours ( $\sim 1$ UT) of 4 April. TEC observations confirm the qualitative behaviour of the F-layer measurements (Figs. 6 and 7 ), though the relative density changes are less distinctive (up to about $65 \%$ increase in plasma density at the F2-layer peak) and the variations are smoother. It is worth noting that a signature of a plasmaspheric mass density increase ( $\sim 20 \%$, as deduced by the $\sim 10 \%$ decrease of $\left.f_{R}\right)$ at the beginning of the main phase is revealed by the FLR observations (Fig. 5). So, the initial positive storm phenomena appear to have a more intense effect at ionospheric heights. Simultaneous density enhancement in the ionosphere and the plasmasphere $(2.5<L<4)$ have been recently found by Chi et 
al. (2005) during the main phase of the famous geomagnetic storm of 29-30 October 2003. FLR observations by Takasaki et al. (2004) and Vellante et al. (2005) also reported for the same storm a plasmaspheric density increase at lower latitudes $(1.4<L<1.8)$. Chi et al. (2005) attributed the density increase to the penetration in the low-latitude ionosphere of the duskward interplanetary electric field, which resulted in an uplifting of the F layer via the $\boldsymbol{E} \times \boldsymbol{B}$ drift. In turn, this leads to an overall increase in the ionization density because of a reduced loss rate (Prölss, 1995; Tsurutani et al., 2004). A similar effect might be responsible for the present observations.

During the subsequent negative storm phase (from $\sim 00: 00$ UT of 4 April until $\sim 11: 00$ UT of 5 April, see Figs. 6, 7 and 8), we observe a density decrease both in the ionosphere and the plasmaphere, with a maximum depletion of about $50 \%$ in both regions. As previously mentioned, the negative storm phase at F2-layer heights is thought to arise mainly from the decrease in the $[\mathrm{O}] /[\mathrm{N} 2]$ ratio, which results in a strong ion loss rate enhancement. This composition disturbance zone propagates equatorward from the auroral region with the disturbance meridional neutral wind of the storm. Depending on the season it can propagate more or less far, and often a steep gradient in the meridional direction is formed (Skoblin and Förster, 1995; Zuzic et al., 1997).

On the other hand, penetration electric fields during storm onset and drifts due to the disturbance dynamo (Blanc and Richmond, 1980) also contribute to the well-known plasmapause displacement during the storm (Carpenter and Lemaire, 1997), as well as to the decrease of plasma density in the outer region within the re-filling plasmasphere. The disturbance dynamo effect is known to persist for many hours due to the neutral air inertia. Unfortunately, direct measurements of the electric drift are not available for this interval at mid- to low-latitudes in this longitudinal sector; however, the disturbance dynamo presumably declines during the second storm day because no further magnetospheric forcing is applied. Therefore, the refilling of the plasmaspheric flux tubes by field-aligned plasma fluxes from the daytime ionosphere regains control. On the other hand, the enhanced ion loss rates in the ionosphere (which caused the density depletion at ionospheric level inside the composition disturbance zone) also leads to a reduced upward ion flux from the ionosphere to the plasmasphere with respect to normal conditions. The refilling process depends linearly on the amount of the average upward ion flux rates and is proportional to $L^{4}$ due to the rapidly increasing flux tube volume. The reduced fluxes retard the full refilling of the flux tubes, whose characteristic time is of the order of one to a few days at these $L$-shells (Krinberg and Tashchilin, 1982).

Lastly, a positive disturbance phase re-establishes at $\sim$ 11:00 UT on 5 April, probably due to the advent of a new magnetospheric disturbance, consistent with the newlydeclining $D$ st values (Fig. 5).

\section{Conclusions}

The first CAWSES campaign has been an effort to operate in a coordinate scheme in the framework of the solar-terrestrial research. Indeed, the joint acquisition and use of data from two or more different instrumentations is not only useful in the whole research field but also represents an added value to the individual data. In this paper we describe the results obtained from the analysis of ULF geomagnetic field variations and ionospheric measurements at low latitude during the campaign, and, in particular, in correspondence to the geomagnetic storm associated with the Earth's arrival of a coronal mass ejection. The principal results of the present investigation can be summarized as follows:

- The whole period is characterized by a moderate Pc3 wave activity during morning hours; its correspondence with small cone angles is clearly indicative of a penetration of upstream wave turbulence generated in the foreshock region. The strong morning/afternoon asymmetry in the Pc3 wave activity does not seem to be related to the IMF orientation in the ecliptic plane, confirming a previous analysis conducted at geosyncronous orbit by Takahashi et al. (1981). Our results indicate that the mechanisms of upstream wave penetration in the magnetosphere still deserve further investigation by the analysis of a larger number of case studies using azimuthally extended ground magnetometer arrays to separate LT and UT dependences.

- The complex SI waveforms are indicative of a significant contribution of the high-latitude ionospheric currents on low-latitude ground measurements. It reinforces the conclusions drawn by Kikuchi and Araki (1985), Tsunomura (1998), Villante et al. (2005a), who showed that at similar latitudes the SI manifestation cannot be interpreted in terms of the magnetopause current alone.

- After the SI occurrence, the power spectra of the $H$ component reveal clear evidence for spectral enhancements matching the magnetospheric cavity/waveguide mode eigenfrequencies. It is interesting to underline in this sense that, as for the present case, most of the events presented in the scientific literature (e.g. Kepko and Spence, 2003; Villante et al., 2005b) typically occurred after the impact of SW shock waves on the magnetopause. This leads one to speculate that, in general, perturbed magnetospheric conditions might be important for the onset of global oscillations of the Earth's magnetosphere. Moreover, the results of the present investigation seem to confirm that some "selected" frequency modes might be an inherent property of the SW (Kepko and Spence, 2003), and also suggest noncompressive Alfvénic SW fluctuations as direct drivers of 
long period geomagnetic field pulsations at "selected" frequencies.

- The FLR remote sensing technique revealed a significant reduction (by a factor of 1.6-2) in the plasmasphere density at $L=1.7-1.8$ during the recovery phase of the geomagnetic storm. This decrease is also accompanied by a significant negative ionospheric storm phase and is confirmed by vertical TEC measurements. It confirms similar observations obtained by completely different techniques (Degenhardt et al., 1977). The typical lack of FLR signatures during nighttime did not allow one to monitor the plasmasphere density by this technique during all phases of the geomagnetic storm. A larger, longitudinally extended, network would be necessary to obtain a more complete picture of the plasmaspheric dynamics taking place during such events. On the other hand, each storm event has its own individual manifestation because of the complex nonlinear interactions of the contributing processes and the large variety of the initial and boundary conditions. An appropriate interplay between global-scale modelling studies (such as those dealing with the composition changes (Namgaladze et al., 2000) or with the interaction of disturbance dynamo electric fields (Maruyama et al., 2005)) and coordinated measurements, such as this first CAWSES Space Weather campaign, is important for the understanding of the complex storm events.

Acknowledgements. The authors thank N. F. Ness for the ACE MFI data and D. J. McComas for the ACE SWE data. We gratefully acknowledge the TEC data supply by and discussions with N. Jakowski from DLR Neustrelitz.

Topical Editor M. Pinnock thanks two referees for their help in evaluating this paper.

\section{References}

Araki, T.: A physical model of the geomagnetic sudden commencement, in: Solar Wind Sources of Magnetospheric Ultra-LowFrequency Waves, edited by: Engebretson, M. J., Takahashi, K., and Scoler, M., Geophys. Mon. vol. 81, AGU, Washington D.C., 183-200, 1994.

Berube, D., Moldwin, M. B., Fung, S. F., and Green, J. L.: A plasmaspheric mass density model and constraints on its heavy ion concentration, J. Geophys. Res., 110, A04212, doi:10.1029/2004JA010684, 2005.

Blanc, M. and Richmond, A. D.: The ionospheric disturbance dynamo, J. Geophys. Res., 85, 1669-1686, 1980.

Buonsanto, M. J.: Ionospheric Storms-a review, Space Sci. Rev., 88, 563-601, 1999.

Carpenter, D. L. and Park, C. G.: On what ionosphere workers should know about the plasmapause-plasmasphere, Rev. Geophys. Space Phys., 11, 133-154, 1973.

Carpenter, D. L. and Lemaire, J.: Erosion and recovery of the plasmasphere in the plasmapause region, Space Sci. Rev., 80, 153179, 1997.
Chi, P. J., Russell, C. T., Musman, S., Peterson, W. K., Le, G., Angelopoulos, V., Reeves, G. D., Moldwin, M. B., and Chun, F. K.: Plasmaspheric depletion and refilling associated with the September 25, 1998 magnetic storm observed by ground magnetometers at L=2, Geophys. Res. Lett., 27, 633-636, 2000.

Chi, P. J., Russell, C. T., Foster, J. C., Moldwin, M. B., Engebretson, M. J., and Mann, I. R.: Density enhancement in plasmasphereionosphere plasma during the 2003 Halloween Superstorm: Observations along the 330th magnetic meridian in North America, Geophys. Res. Lett., 32, L03S07, doi:10.1029/2004GL021722, 2005.

Clilverd, M. A., Menk, F. W., Milinevski, G., et al.: In situ and ground-based intercalibration measurements of plasma density at $\mathrm{L}=2.5$, J. Geophys. Res., 108(A10), 1365, doi:10.1029/2003JA009866, 2003.

Degenhardt, W., Hartmann, G. K., and Leitinger, R.: Effects of a magnetic storm on the plasmaspheric electron content, J. Atmos. Terr. Phys., 39, 1435-1440, 1977.

Förster, M. and Jakowski, N.: Geomagnetic storm effects on the topside ionosphere and plasmasphere: A compact tutorial and new results, Surveys in Geophys., 21, 47-87, 2000.

Francia, P. and Villante, U.: Some evidence of ground power enhancements at frequencies of global magnetospheric modes at low latitude, Ann. Geophys., 15, 17-23, 1997.

Francia, P., Lepidi, S., Villante, U., Di Giuseppe, P., and Lazarus, A. J.: Geomagnetic response at low latitude to continuous solar wind pressure variations during northward interplanetary magnetic field, J. Geophys. Res., 104, 19923-19930, 1999.

Greenstadt, E. W.: Field-determined oscillations in the magnetosheath as possible source of medium-period, daytime micropulsations, in: Proceedings of the Conference on solar Terrestrial Relations, edited by: Venkatesan, D., University of Calgary, Calgary, Alta, 515, 1973.

Greenstadt, E. W. and Olson, J. V.: Geomagnetic pulsation signals and hourly distributions of IMF orientation, J. Geophys. Res., 84, 1493-1498, 1979.

Heise, S., Jakowski, N., Wehrenpfennig, A., Reigber, C., and Lühr, H.: Sounding of the topside ionosphere/plasmasphere based on GPS measurements from CHAMP: Initial results, Geophys. Res. Lett., 29(14), doi:10.1029/2002GL014738, 2002.

Jakowski, N.: TEC monitoring by using satellite positioning systems, in: Modern Ionospheric Science, edited by: Kohl, H., Rüster, R., and Schlegel, K., European Geophysical Society, Katlenburg-Lindau, ProduServ GmbH Verlagsservice, Berlin, 371-390, 1996.

Jakowski, N., Wehrenpfennig, A., Heise, S., Reigber, C., Lühr, H., Grunwaldt, L., and Meehan, T.K.: GPS radio occultation measurements of the ionosphere from CHAMP: Early results, Geophys. Res. Lett., 29(10), doi:10.1029/2001GL014364, 2002.

Kepko, L. and Spence, H.E.: Observations of discrete, global magnetospheric oscillations directly driven by solar wind density variations, J. Geophys. Res., 108 (A6), 1257, doi:10.1029/2002JA009676, 2003.

Kepko, L., Spence, H. E., and Singer, H. J.: ULF waves in the solar wind as direct drivers of magnetospheric pulsations, Geophys. Res. Lett., 29 (8), 1197, doi:10.1029/2001GL014405, 2002.

Kessel, R. L., Mann, I. R., Fung, S. F., Milling, D. K., and O'Connell, N.: Correlation of Pc5 wave power inside and outside themagnetosphere during high speed streams, Ann. Geo- 
phys., 22, 629-641, 2004.

Kikuchi, T. and Araki, T.: Preliminary positive impulse of geomagnetic sudden commencement observed at dayside middle and low latitudes, J. Geophys. Res., 90, 12 195-12 200, 1985.

Kivelson, M. and Southwood, D.: Resonant ULF waves: a new interpretation, Geophys. Res. Lett., 12, 49-52, 1985.

Kivelson, M. and Southwood, D.: Coupling of global magnetospheric MHD eigenmodes to field line resonances, J. Geophys. Res., 91, 4345-4351, 1986.

Krinberg, I. A. and Tashchilin, A. V.: Refilling of geomagnetic force tube with a thermal plasma after magnetic disturbances, Ann. Geophys., 38, 25-32, 1982.

Lepidi, S., Francia, P., Villante, U., Meloni, A., Lazarus, A. J., and Lepping, R. P.: The Earth's passage of the 11 April 1997 coronal ejecta: geomagnetic field fluctuations at high and low latitude during northward interplanetary magnetic field conditions, Ann. Geophys., 17, 1245-1250, 1999.

Maruyama, N., Richmond, A. D., Fuller-Rowell, T. J., Codrescu, M. V., Sazykin, S., Toffoletto, F. R., Spiro, R. W., and Millward, G. H.: Interaction between direct penetration and disturbance dynamo electric fields in the storm-time equatorial ionosphere, Geophys. Res. Lett., 32, L17105, doi:10.1029/2005GL023763, 2005.

Mathie, R. A., Mann, I. R., Menk, F. W., and Orr, D.: Pc5 ULF pulsations associated with waveguide modes observed with the IMAGE magnetometer array, J. Geophys. Res., 104, 7025-7036, 1999.

Matsushita, S.: A Study of the Morphology of Ionospheric Storms, J. Geophys. Res., 64, 305-321, 1959.

Menk, F. W., Orr, D., Clilverd, M. A., Smith, A. J., Waters, C. L., Milling, D. K., and Fraser, B. J.: Monitoring spatial and temporal variations in the dayside plasmasphere using geomagnetic field line resonances, J. Geophys. Res., 104, 19955-19969, 1999.

Namgaladze, A. A., Förster, M., and Yurik, R. Y.: Analysis of the positive ionospheric response to a moderate geomagnetic storm using a global numerical model, Ann. Geophys., 18, 461-477, 2000

Olson, J. V: Pi2 pulsations and substorm onsets: a review, J. Geophys. Res., 104, 17 499-17 520, 1999.

Orr, D. and Matthew, J. A. D.: The variation of geomagnetic micropulsation periods with latitude and the plasmapause, Planet. Space Sci., 19, 897-905, 1971.

Pezzopane, M.: Interpre: a Windows software for semiautomatic scaling of ionospheric parameters from ionograms, Computers \& Geosciences, 30, 125-130, 2004.

Posch, L. J., Engebretson, M. J., Pilipenko, V. A., Hughes, W. J., Russell, C. T., and Lanzerotti, L. J.: Characteristics of longperiod ULF response to magnetic storms, J. Geophys. Res., 108 (A1), 1029, doi:101029/2002JA009386, 2003.

Prölss, G. W.: Ionospheric F-region storms, in: Handbook of Atmospheric Electrodynamics, Vol. 2, edited by: Volland, H., CRC Press, Boca Raton, 195-248, 1995.

Radoski, H. R.: A theory of latitude dependent geomagnetic micropulsations: the asymptotic fields, J. Geophys. Res., 79, 595-603, 1974.

Reinisch, B. W.: Modern Ionosondes, in: Modern Ionospheric Science, edited by: Kohl, H., Rüster, R., and Schlegel, K., European Geophysical Society, Katlenburg-Lindau, Germany, 440458,1996
Reinisch, B. W. and Huang, X.: Automatic calculation of electron density profiles from digital ionograms, 3 . Processing of bottomside ionograms, Radio Science, 18, 477-492, 1983.

Rishbeth, H.: How the thermospheric circulation affects the ionospheric F2-layer, J. Atmos. Solar-Terr. Phys., 60, 1385-1402, 1998.

Russell, C. T., Luhmann, J. G., Odera, T. J., and Stuart, W. F.: The rate of occurrence of dayside Pc3,4 pulsations: the L-value dependence of the IMF cone angle effect, Geophys. Res. Lett., 10, 663-666, 1983.

Samson, J. C., Greenwald, R. A., Ruohoniemi, J. M., Hughes, T. J., and Wallis, D. D.: Magnetometer and radar observations of MHD cavity modes in the Earth's magnetosphere, Can. J. Phys., 69, 929-937, 1991

Samson, J. C., Harrold, B. G., Ruohoniemi, J. M., Greenwald, R A., and Walker, A. D. M.: Field line resonances associated with MHD waveguides in the magnetosphere, Geophys. Res. Lett., 19, 441-444, 1992.

Schulz, M.: Eigenfrequencies of geomagnetic field lines and implications for plasma-density modeling, J. Geophys. Res., 101, 17385-17 397, 1996.

Shimazu, H., Araki, T., Kamei, T., and Hanado, H.: A symmetric appearence of Pc5 on dawn and dusk side associated with solar wind dynamic pressure enhancement, J. Geomag. Geoelect., 47, 177-189, 1995.

Skoblin, M. G. and Förster, M.: Steep latitudinal gradients of thermospheric composition during magnetic storms: A possible formation mechanism, Ann. Geophys., 13, 277-284, 1995.

Sutcliffe, P. R., Hattingh, S. K. F., and Boshoff, H. F. V.: Longitudinal effects on the eigenfrequencies of low-latitude Pc 3 pulsations, J. Geophys. Res., 92, 2535-2543, 1987.

Takahashi, K., McPherron, R. L., Greenstadt, E. W., and Neeley, C. A.: Factors controlling the occurrence of Pc3 magnetic pulsations at synchronous orbit, J. Geophys. Res., 86, 5472-5484, 1981.

Takasaki, S., Kawano, H., Tanaka, Y., Yoshikawa, A., Seto, M., Iizima, M., and Yumoto, K.: Density perturbations in the inner plasmasphere during huge magnetic storms in October-November 2003: Ground-based observations, Eos Trans. AGU, 85(17), Jt. Assem. Suppl., Abstract SH53A-11, 2004.

Troitskaya, V. A. and Bolshakova, O. V.: Diagnostics of the magnetosphere using multipoint measurements of ULF-waves, Adv Space Res., 8, 413-425, 1988.

Tsunomura, S.: Characteristics of geomagnetic sudden commencement observed in middle and low latitudes, Earth Planets and Space, 50, 755-772, 1998.

Tsurutani, B., Mannucci, A., Iijima, B., et al.: Global dayside ionospheric uplift and enhancement associated with interplanetary electric fields, J. Geophys. Res., 109, A08302, doi:10.1029/2003JA010342, 2004.

Vellante, M., De Lauretis, M., Villante, U., Adorante, N., Piancatelli, A., Schwingenschuh, K., Magnes, W., Koren, W. and Zhang, T. L.: A new meridional array in middle-south europe for monitoring dynamic processes in the coupled system plasmasphere-ionosphere, in: SOLSPA 2001: Proceedings of the Second Solar Cycle and Space Weather Euroconference, ESA Spec. Publ. 477, edited by: Sawaya-Lacoste, H., Eur. Space Agency, Noordwijk, Netherlands, 487-490, 2002.

Vellante, M., Förster, M., Zhang, T. L., Villante, U., De Lauretis, 
M., and Magnes, W.: Remote sensing of the plasmasphere mass density during geomagnetic storms by ULF waves recorded at low latitudes $(1.6<\mathrm{L}<1.9)$, paper presented at the Xth IAGA Scientific Assembly, Toulouse, 18-29 July, 2005.

Villante, U. and Di Giuseppe, P.: Some aspects of the geomagnetic response to solar wind pressure variations: a case study at low and middle latitudes, Ann. Geophys., 22, 2053-2066, 2004.

Villante, U., Francia, P., Lepidi, S., De Lauretis, M., Pietropaolo, E., Cafarella, L., Meloni, A., Lazarus, A. J., Lepping, R. P., and Mariani, F.: Geomagnetic field variations at low and high latitude during the January 10-11, 1997 magnetic cloud, Geophys. Res. Lett., 25, 2593-2596, 1998.

Villante, U., Francia, P., and Lepidi, S.: Pc5 geomagnetic field fluctuations at discrete frequencies at a low latitude station, Ann. Geophys., 19, 321-325, 2001.

Villante, U., Lepidi, S., Francia, P., and Bruno, T.: Some aspects of the interaction of interplanetary shocks with the Earth's magnetosphere: an estimate of the propagation time through the magnetosheath, J. Atm. Solar-Terr. Phys., 66, 337-341, 2004.

Villante, U., Piersanti, M., Di Giuseppe, P., Vellante, M., Zhang, T. L., and Magnes, W.: Sudden commencement event of 17 April 2002: Aspects of the geomagnetic response at low latitudes, J. Geophys. Res., 110, A12S23, doi:10.1029/2004JA010978, 2005a.

Villante, U., Nubile, A., Di Giuseppe, P., Francia, P., and Vellante, M.: ULF oscillations at discrete frequencies: a comparison between ground, magnetospheric and interplanetary measurements, Proceedings of the Solar Variability and Earth Climate Conference (27 June-1th July, 2005, Monte Porzio Catone, Rome), Mem. SAIt., 76, 1060-1063, 2005b.
Walker, A. D. M., Ruohoniemi, J. M., Baker, K. B., Greenwald, R. A., and Samson, J. C.: Spatial and temporal behavior of ULF pulsations observed by Goose Bay HF radar, J. Geophys. Res., 97, 12 187-12 202, 1992.

Waters, C. L., Menk, F. W., and Fraser, B. J.: The resonance structure of low latitude Pc3 geomagnetic pulsations, Geophys. Res. Lett., 18, 2293-2296, 1991.

Yumoto, K.: Generation and propagation mechanisms of lowlatitude magnetic pulsations - a review, J. Geophys., 60, 79-105, 1986.

Ziesolleck, C. W. S. and Chamalaun, F. H.: A two-dimensional array study of low-latitude Pc5 geomagnetic pulsations, J. Geophys. Res., 98, 13 703-13 713, 1993.

Ziesolleck, C. W. S. and McDiarmid, D. R.: Statistical survey of auroral latitude Pc5 spectral and polarization characteristics, J. Geophys. Res., 100, 19299-19312, 1995.

Zolesi, B., Belehaki, A., and De Franceschi, G.: On the potential applicability of the Simplified Ionospheric Regional Model to different midlatitude areas, Radio Science, 31(3), 547-552, 1996.

Zuzic, M., Scherliess, L., and Prölss, G. W.: Latitudinal structure of thermospheric composition perturbations, J. Atmos. Sol. Terr. Phys., 59, 711-724, 1997. 